\title{
Managing Macular Holes in a Developing Economy
}

\author{
Bassey Fiebai, Chinyere N. Pedro-Egbe \\ Department of Ophthalmology, University of Port Harcourt Teaching Hospital, \\ Port Harcourt, Nigeria \\ Email: bassief@yahoo.com
}

Received 19 May 2015; accepted 16 August 2015; published 19 August 2015

Copyright (C) 2015 by authors and Scientific Research Publishing Inc.

This work is licensed under the Creative Commons Attribution International License (CC BY).

http://creativecommons.org/licenses/by/4.0/

(c) (i)

Open Access

\section{Abstract}

Background: Macular holes are the common cause of visual impairment especially in the elderly and have a variety of etiological factors. The advances in the management of macular holes are encouraging and are now available in developing countries although scarce, where hitherto; patients seek attention outside their country. The need to understand this disease has therefore become pertinent in all retina clinics. Objective: To evaluate the pattern of presentation of macular holes and its management in a retina clinic in South South Nigeria. Methods: A 5 year retrospective, non comparative review of 24 consecutive cases presenting to a retinal clinic was carried out. Relevant information was extracted from the medical records and analyzed. Results: Three hundred and sixty four cases were seen between January 2009 and December 2013. Twenty four cases had macular holes and ten (41.7\%) had bilateral presentation with a total of 34 eyes. The incidence of macular holes was $6.6 \%$. The mean age was 46 years $(S D \pm 13.42)$ with a female preponderance, 5:1. Idiopathic holes formed the bulk of the cases 14(58.3\%); others were trauma 4(16.7\%), posterior uveitis $2,(8.3 \%)$, chemotherapy $2(8.3 \%)$, Solar retinopathy and retinitis pigmentosa 1 $(4.2 \%)$. Nineteen $(55.9 \%)$ of the 34 eyes were visually impaired (BCVA $<6 / 18)$. Nineteen eyes had full thickness holes $(55.9 \%)$ requiring surgery, however only $3(12.5 \%)$ of these could afford to have surgery with one reoperation. Four patients $(16.7 \%)$ had complications in form of retinal detachments at presentation. Conclusion: This study has shown that the incidence of macular holes in the developing world is significant and resources to manage these cases are grossly lacking. Specialist training, with government subsidizing costs will alleviate these difficulties and reduce visual loss from macular holes.

\section{Keywords}

Developing Economy, Macula Hole, Pattern, Management 


\section{Introduction}

Macular holes are full thickness openings of the neurosensory retina in the centre of the fovea from the internal limiting membrane to the outer segment of the photoreceptor layer [1]. Since the fovea is replete with cones, this defect subsequently leads to a drop in central vision and metarmorphopsia [1] [2].

Even though macula holes were originally described by Knapp in relation to trauma [3], it is commoner to find them now in non traumatic settings [2]-[4]. Kunt was the first to describe non traumatic macular holes and this was buttressed by other studies showing that majority of macular holes are idiopathic, occurring in eyes with no previous pathology [4] [5].

Trauma related macular holes are believed to result from a transmission of concussive form in a contrecoup manner, while idiopathic holes are believed to result from focal shrinkage of the prefoveal cortical vitreous, with persistent adherence of the vitreous to the fovealregion [5] [6]. Other etiological factors that have been shown to cause macular holes include myopia, trauma, and solar retinopathy [1]. Macular holes have also been reported and presumed to be secondary to other conditions such as accidental laser burns, retinitis pigmentosa, complications of chemotherapy, posterior uveitis and branch retinal vein occlusion [7]-[11]. By and large, the pathogenesis is still incompletely understood and is believed to be an interplay between vitreomacular traction and some form of degenerative dissolution of inner retinal layers in the fovea [12].

The diagnosis and management of this condition have become more encouraging with the use of Optical coherence tomography (OCT) and the clinical staging of the disease by Gass. OCT affords the ophthalmologist a high resolution cross sectional examination of the macular and provides information concerning diagnosis, classification and aetiology of macular holes. The revolution in the management of macular hole with vitrectomy, cortical vitreous peeling by Kelly and Wendel, resulting in a good anatomical outcome, fovealreappositioning and a subsequent improvement in visual outcome further piqued the interest of retinal specialists globally and in the developing world [13].

Even though the excitement of ophthalmologists in developing countries towards these milestones is short lived, as these equipments are not readily available coupled with lack of the requisite expertise, the need to understand this disease entity, its pattern of presentation, diagnosis, management and prognosis has become pertinent in all retinal clinics as macular hole surgery is now available in Nigeria,

\section{Materials and Methods}

This study was a 5 year retrospective non comparative review of the medical records of 24 consecutive patients who presented to the retina clinic of the eye department of University of Port Harcourt Teaching Hospital between January 2009-December 2013. Data extracted included demographic data such as age and sex; others were best corrected visual acuity on presentation (BCVA) and other relevant clinical information. The diagnosis of a macula hole was made based on the history of the known risk factors and clinical findings of a macular lesion with biomicrsoscopy. Staging of the macular hole was done according to the Gass classification. Stage 1 was a macular cyst, stage 2; early full thickness macular hole, stage 3; fully developed macular hole with posterior vitreous attachment and stage 4; fully developed macular hole with complete vitreous separation. Fundal examinations were carried out with 90D stereoscopic lens, and a mydriatic fundus photograph. Optical coherence tomography (Stratus OCT, Carl Zeiss Meditec Inc., USA) was used to confirm the diagnosis, classification and complications of macular hole.

Information from each subject was entered into a spreadsheet using the Statistical Package for Social Sciences (SPSS) 11.0 for Windows statistical software and analysed. Bivariate analysis involved the use of chi-square test and Fisher exact test for testing the significance of associations between categorical variables. P values of 0.05 and below were considered statistically significant.

\section{Results}

A total of 24 subjects comprising 20 females and 4 males were seen over the 5 year period and diagnosed with macular holes. Ten subjects had bilateral holes (41.7\%) as shown in Table 1 . The mean age was 46 years (SD \pm 13.42). Females were more affected with a ratio of 5:1. Table 2 shows the age and gender distribution of the patients.

The hospital incidence of macular holes was 6.6\%. 
Table 1. Laterality of macula hole in the 24 patients.

\begin{tabular}{ccc}
\hline Eye & Frequency & Percentage \\
\hline BIL & 10 & 41.7 \\
LT & 7 & 29.2 \\
RT & 7 & 29.2 \\
Total & $\mathbf{2 4}$ & $\mathbf{1 0 0 . 0}$ \\
\hline
\end{tabular}

Bilateral—BIL, Left—LT, Right-RT.

Table 2. Age and gender distribution of patients with macular holes.

\begin{tabular}{ccc}
\hline Age group (years) & Gender male & Total (\%) female \\
\hline $1(4.2)$ & $2(8.3)$ & $3(12.5)$ \\
$0(0.0)$ & $5(20.8)$ & $5(20.8)$ \\
$0(0.0)$ & $4(16.7)$ & $4(16.7)$ \\
$2(8.3)$ & $6(25.0)$ & $8(33.3)$ \\
$1(4.2)$ & $3(12.5)$ & $4(16.7)$ \\
$4(16.7)$ & $20(83.3)$ & $24(100.0)$
\end{tabular}

Chi-square $=2.89 ; \mathrm{df}=4 ; \mathrm{p}$-value $=0.577(\mathrm{p}$-value not significant $(\mathrm{p}>0.05)$.

Table 1 shows that 10 (41.7\%) out of the 24 cases had macular holes in both. eyes.

There were numerous etiological factors seen, but idiopathic presentation (58.3\%) was the commonest as shown in Table 3. Others were trauma 4 (16.7\%), posterior uveitis 2, (8.3\%), chemotherapy 2 (8.3\%), Solar retinopathy and retinitis pigmentosa 1 (4.2\%). Nineteen (55.9\%) of the 34 eyes were visually impaired (BCVA < $6 / 18$ ). Nineteen eyes had full thickness holes (55.9\%) requiring surgery, however only 3 (12.5\%) of these could afford to have surgery with one reoperation. Four patients (16.7\%) had complications in form of retinal detachments at presentation.

Table 4 shows that there was no statistically significant difference between risk factors and the age of the subjects.

Table 5 shows the distribution of visual acuity of the patients. Nineteen (55.9\%) of the 34 eyes were visually impaired (BCVA < 6/18). Nineteen eyes had full thickness holes (55.9\%) requiring surgery as shown in Table 6, however only 3 (12.5\%) of these could afford to have surgery with one reoperation.

3 out of the 24 patients had the macular hole surgery.

As illustrated in Table 7, four patients (16.7\%) had complications in form of retinal detachments at presentation.

\section{Discussion}

Twenty four cases of macular holes were seen in this study with ten (41.7\%) cases presenting bilaterally (Table 1) giving a total of 34 eyes. This appears to be higher than what is recorded in other studies probably due to the late presentation and intervention which are common factors in the developing world [14] [15]. Table 2 shows that the mean age was 46 years ( $S D \pm 13.42$ ) with a female preponderance. The mean age here is at variance with other studies where the mean age is higher because most of the available studies focused on idiopathic macular holes and other aetiological factors were not reported [15]. Females accounted for $83.3 \%$ of the study group with a female to male ratio of 5:1 [14]. This is consistent with other studies and lends credence to the postulations implicating hormonal changes [2] [14] [15]. The hospital incidence of macular holes was $6.6 \%$ of persons and $9.3 \%$ of eyes. There is a dearth of studies on incidence of macular holes. Most studies report prevalence [16]-[18]. However a population based incidence reported 7.8 persons and 8.69 eyes per 100,000 population [14]. Our incidence is quite significant considering that it is a hospital based study with a smaller 
Table 3. Shows the risk factors at presentation of the 24 patients.

\begin{tabular}{ccc}
\hline Risk Factors & Frequency & Percentage (\%) \\
\hline Idiopathic & 14 & 58.3 \\
Trauma & 4 & 16.7 \\
Posterior Uveitis & 2 & 8.3 \\
Chemotherapy & 2 & 8.3 \\
Solar Retinopathy & 1 & 4.2 \\
Retinitis Pigmentosa & 1 & 4.2 \\
Total & $\mathbf{2 4}$ & $\mathbf{1 0 0}$ \\
\hline
\end{tabular}

Table 4. Relationship between risk factor and age.

\begin{tabular}{ccccccc}
\hline Risk Factors & \multicolumn{5}{c}{ Age Group } & Total \\
\hline & $\mathbf{3 0}$ & $\mathbf{3 1 - \mathbf { 4 0 }}$ & $\mathbf{4 1 - \mathbf { 5 0 }}$ & $\mathbf{5 1 ~ - \mathbf { 6 0 }}$ & $>\mathbf{6 0}$ & \\
Ca Breast & 0 & $1(4.2)$ & 0 & 0 & 0 & $1(4.20)$ \\
Ca Prostate & 0 & 0 & 0 & 0 & $1(4.2)$ & $1(4.2)$ \\
RP & 0 & $1(4.2)$ & 0 & 0 & 0 & $1(4.2)$ \\
Idiopathic & $1(4.2)$ & 0 & 4 & $6(25.0)$ & $3(12.5)$ & $14(58.3)$ \\
Post Uveitis & $1(4.2)$ & 0 & 0 & $1(4.2)$ & 0 & $2(8.3)$ \\
Solar & $1(4.2)$ & 0 & 0 & 0 & 0 & $1(4.20$ \\
Trauma & 0 & $3(12.5)$ & 0 & $1(4.2)$ & 0 & $4(16.7)$ \\
Total & $\mathbf{3 ( 1 2 . 5 )}$ & $\mathbf{5 ( 2 0 . 8 )}$ & $\mathbf{4 ( \mathbf { ( 1 6 . 7 ) }}$ & $\mathbf{8 ( 3 3 . 3 )}$ & $\mathbf{4 ( 1 6 . 7 )}$ & $\mathbf{2 4}(\mathbf{1 0 0 . 0})$ \\
\hline
\end{tabular}

Chi-square $=35.65 ; \mathrm{df}=24 ; \mathrm{p}$-value $=0.0593$.

Table 5. Best corrected visual acuity at presentation.

\begin{tabular}{ccc}
\hline Visual acuity & Number $(\mathrm{n}=34$ eyes $)$ & Percentage \\
\hline$<6 / 18$ & 15 & 44.1 \\
$6 / 18-6 / 60$ & 16 & 47.1 \\
$>6 / 60$ & 3 & 8.8 \\
Total & 34 & 100 \\
\hline
\end{tabular}

Table 6. Macula hole staging in 34 eyes.

\begin{tabular}{ccc} 
Stage & Number $(\mathrm{n}=34$ eyes $)$ & Percentage \\
0 & 7 & 20.6 \\
1 & 3 & 11.8 \\
2 & 4 & 23.5 \\
3 & 8 & 20.6 \\
4 & 7 & $\mathbf{1 0 0}$ \\
Total & $\mathbf{3 4}$ & $\mathbf{0 0}$ \\
\hline
\end{tabular}


Table 7. Proportion of patients with complications.

\begin{tabular}{ccc}
\hline Risk Factor & Frequency (\%) & Complications-RD (\%) \\
\hline Idiopathic & $14(58.3)$ & $3(12.5)$ \\
Trauma & $4(16.7)$ & $1(4.2)$ \\
Posterior Uveitis & $2(8.3)$ & - \\
Chemotherapy & $2(8.3)$ & - \\
Solar Retinopathy & $1(4.2)$ & - \\
Retinitis Pigmentosa & $1(4.2)$ & $\mathbf{4 ( 1 6 . 7 )}$ \\
Total & $\mathbf{2 4 ( 1 0 0 )}$ &
\end{tabular}

RD—Retinal detachment.

sample size. The commonest aetiological factor in this series was idiopathic macular holes just as reported widely (Table 3). Again there is very little documentation on other causes of macular holes as most studies focus on idiopathic holes [15]. Idiopathic macular hole commonly affects otherwise healthy individuals in their $6^{\text {th }}$ or $7^{\text {th }}$ decade and prefoveola traction have been widely accepted as the pathogenesis implicated in idiopathic macular hole [2].

Trauma contributed to 4 of the cases, while 2 of the cases resulted from poorly treated posterior uveitis resulting in vitreoretinal traction and retinal detachment. Photochemical changes in the retina with increased temperature while sun gazing is believed to cause macular damage [19] [20]. One case of solar retinopathy was seen in our study. Two cases were attributed to chemotherapy following breast cancer and prostate cancer. Tamoxifen retinopathy though rare has been reported to cause foveal cysts that could lead to macular holes [9]. The female patient who was on Tamoxifen therapy was 32 years old which ruled out a typical idiopathic etiology, while the other was male. Both had bilateral presentation which was a pointer to a systemic aetiology. Table 4 shows that there was no statistically significant difference between the risk factors and age of subject in this study, a larger study however will most likely demonstrate this. Central vision loss is the commonest manifestation of macular holes and can be visually disabling. Out of the 34 eyes more than half, had low vision $(<6 / 18)$ from macular hole (19 eyes (55.9\%)) and presented with full thickness holes (Table 5 and Table 6).

Retinal detachment is the most common complication following the development of macular hole as subretinal fluid insinuates between the neurosensory retina and retinal pigment epithelium through this defect to cause a detachment. In our study 4 patients had retinal detachment at presentation.

The management of macular holes was revolutionized by Kelly and Wendel with vitrectomy, internal limiting membrane peeling and tamponade. Though macular hole surgery is now available in a few private centers in Nigeria, majority who require this service, utilize the government health centers and have to travel long distances to access this specialized service at high costs.

The private centres were these services are available, are all located in the South West geopolitical zones. Rivers State is located in the South South geopolitical zone of the country with about 19 Ophthalmologists. There is only one ophthalmologist trained in Medical Retina and there are no facilities for vitrectomy in the state presently. Patients therefore have no option but to travel out of their state of residence to access this service with the attendant risks and heavy costs.

Even though 19 eyes in this series had full thickness holes that required surgery, only 3 patients could afford surgery, with one requiring reoperation. The direct cost of surgery and the fact that surgery had to be done outside the residence of abode were factors that militated against the take up of this service outside.

\section{Conclusion}

This study has shown that the incidence of macular holes in the developing world is significant and resources to manage these cases are grossly lacking. Specialist training, with government subsidizing costs will alleviate these difficulties and reduce visual loss from macular holes.

\section{References}

[1] Oh, K.T. (2013) Macular Hole Treatment and Management. http://http:emedicine.medscape.com/article/1224320 
[2] Ezra, E. (2001) Idiopathic Full Thickness Macular Hole: Natural History and Pathogenesis. British Journal of Ophthalmology, 85, 102-108.

[3] Knapp, H. (1869) UeberIsolirtezerreissungen der aderhautinfolge von traumen auf augapfel. Archives of Ophthalmology and Otology (Archiv für Augen- und Ohrenheilkunde), 1, 6-29.

[4] Kuhnt, H. (1900) Tber eineeigentumlicheveranderung der netzhautadmaculam (retinitis atrophicanssiverareficanscentralis). Zeitschrift für Augenheilkunde, 3, 105.

[5] Gass, J.D. (1988) Idiopathic Senile Macular Hole. Its Early Stages and Pathogenesis. Archives of Ophthalmology, 106, 629-639. http://dx.doi.org/10.1001/archopht.1988.01060130683026

[6] Aaberg, T.M. (1970) Macular Holes. A Review. Survey of Ophthalmology, 15, 139-162.

[7] Gao, L., Dong, F. and Chan, W. (2007) Traumatic Macular Hole Secondary to Nd: YAG Laser. Eye, 21, 571-573.

[8] García-Fernández, M., Castro-Navarro, J. and Bajo-Fuente, A. (2013) Unilateral Recurrent Macular Hole in a Patient with Retinitis Pigmentosa: A Case Report. Journal of Medical Case Reports, 7, 69. http://dx.doi.org/10.1186/1752-1947-7-69

[9] Eisner, A. and Luoh, S.W. (2011) Breast Cancer Medications and Vision: Effects of Treatments for Early-Stage Disease. Current Eye Research, 10, 867-885.

[10] Bonnin, N., Cornut, P., Chaise, F., Labeille, E., Manificat, H., Feldman, A., Perard, L., Bacin, F., Chiambaretta, F. and Burillon, C. (2013) Spontaneous Closure of Macular Holes Secondary to Posterior Uveitis: Case Series and Literature Review. Journal of Ophthalmic Inflammation and Infection, 3, 34. http://dx.doi.org/10.1186/1869-5760-3-34

[11] Leibovitch, I., Azmon, B., Pianka, P., Alster, Y. and Loewenstein, A. (2003) Macular Hole Secondary to Branch Retinal Vein Occlusion Diagnosed by Retinal Thickness Analyzer. Ophthalmic Surgery, Lasers \& Imaging, 34, 53-56.

[12] Smiddy, W.E. and Flynn Jr., H.W. (2004) Pathogenesis of Macular Holes and Therapeutic Implications. American Journal of Ophthalmology, 137, 525-537. http://dx.doi.org/10.1016/j.ajo.2003.12.011

[13] Kelly, N.E. and Wendel, R.T. (1991) Vitreous Surgery for Idiopathic Macular Holes. Results of a Pilot Study. Archives of Ophthalmology, 109, 654-659. http://dx.doi.org/10.1001/archopht.1991.01080050068031

[14] McCannel, C.A., Ensminger, J.L., Diehl, N.N. and Hodge, D.N. (2009) Population Based Incidence of Macular Holes. Ophthalmology, 116, 1366-1369. http://dx.doi.org/10.1016/j.ophtha.2009.01.052

[15] Sen, P., Bhargava, A., Vijaya, L. and George, R. (2008) Prevalence of Idiopathic Macular Hole in Adult Rural and Urban South Indian Population. Clinical and Experimental Ophthalmology, 36, 257-260. http://dx.doi.org/10.1111/j.1442-9071.2008.01715.x

[16] Klein, R., Klein, B.E., Wang, Q. and Moss, S.E. (1994) The Epidemiology of Retinal Membranes. Transactions of the American Ophthalmological Society, 92, 403-425.

[17] Rahmani, B., Tielsch, J.M., Katz, J., Gottsch, J., Quigley, H., Javitt, J., et al. (1996) The Cause-Specific Prevalence of Visual Impairment in an Urban Population. Baltimore Eye Survey. Ophthamology, 103, 1721-1726. http://dx.doi.org/10.1016/S0161-6420(96)30435-1

[18] Mitchell, P., Smith, W., Chey, T., Wang, J.J. and Chang, A. (1997) Prevalence and Associations of Epiretinal Membranes. The Blue Mountains Eye Study, Australia. Ophthalmology, 104, 1033-1040. http://dx.doi.org/10.1016/S0161-6420(97)30190-0

[19] Comander, J., Gardiner, M. and Loewenstein, J. (2011) High-Resolution Optical Coherence Tomography Findings in Solar Maculopathy and the Differential Diagnosis of Outer Retinal Holes. American Journal of Ophthalmology, 152, 413-419. http://dx.doi.org/10.1016/j.ajo.2011.02.012

[20] Macarez, R., Vanimschoot, M., Ocamica, P. and Kovalski, J.L. (2007) Optical Coherence Tomography Follow-Up of a Case of Solar Maculopathy. Journal Français d'Ophtalmologie, 30, 276-280.

http://dx.doi.org/10.1016/S0181-5512(07)89590-8 